\begin{tabular}{|l|l|}
\hline Recibido / Received & 21 de mayo de 2018 \\
\hline AcEPTAdo / AcEPTED & 10 de junio de 2020 \\
\hline PÁGinas / PAges & De la 151 a la 154 \\
\hline
\end{tabular}

\title{
¿Postcristianismo? \\ El malestar y las esperanzas de Occidente
}

\section{Autor / Author}

SCOLA, Angelo

Editorial / Publishing company

ENCUENTRO, Madrid 2018

DOI: https://doi.org/10.32466/eufv-rel.2020.7.363.151-154

cardenal Scola nos tiene acostumbrados a que sus escritos salgan al paso de las inquietudes que palpitan tras la superficie de los distintos movimientos intelectuales o culturales. Este último libro no abandona ese estilo, tan de agradecer. Sobre todo porque no es fácil discernir la cuestión de fondo que apela desde el corazón humano en cada uno de los gritos que aturden en la esfera pública. Leer al cardenal Scola, por lo tanto, ayuda a educar la mirada sobre la realidad, algo que todos necesitamos hacer, y creo que particularmente quienes desde la universidad tenemos como misión esencial no la de ser meros transmisores de información o críticos de ideas, sino buscadores inquietos de la verdad. La primera frase del texto nos sitúa con claridad en este camino:

\begin{abstract}
El corazón de todo hombre, especialmente del hombre contemporáneo, por muy confuso que pueda ser su vagar por los caminos de la vida, grita esperando una salvación encontrable en un rostro humano. ¿Qué enigma es mi propio «yo»? Hoy existo, ayer no y mañana dejaré de existir. Al comienzo del tercer milenio, en nuestras sociedades en transición y con expresiones muy diferentes entre sí -incluso contradictorias y violentas - el hombre contemporáneo está atravesando por algunas preguntas radicales que no dejan de cuestionarle (Scola, 2018: 9).
\end{abstract}

La postmodernidad parece ya una etiqueta epocal que ha quedado para designar un período objeto de estudio en cursos de verano. Pero los distintos autores que dieron fe en sus escritos del fin de las ideologías, de ese fin de siglo y milenio, se limitaban a eso, a levantar acta de una defunción, pero daba la sensación de que les quedaba grande la tarea de abordar las preguntas radicales que ese fracaso dejaba a la intemperie. «Hace ya muchos años que vivo como hombre desterrado de lo más profundo de mi personali- 
dad y, al mismo tiempo, condenado a indagarla a fondo" es la descripción de Karol Wojtyla que trae a colación Scola precisamente como diagnóstico del malestar que afecta al corazón del hombre contemporáneo, y que las ideologías solo camuflaban, no atendían (Scola, 2018: 10). O que el narcisismo individualista enmascara sumiéndole en una soledad mayor. ¿Entonces?

La ausencia de vínculos y la falta de libertad hacen que [el hombre postmoderno] perciba con radicalidad que la esperanza no puede derivar simplemente de que las circunstancias cambien: es demasiado poco. Ni un nuevo sistema intelectual, ni una nueva técnica de introspección, ni una nueva teoría social, serán capaces de que volvamos a alzar la mirada (Scola, 2018: 11).

Este es el campo de juego en el que se mueve la reflexión a un tiempo provocadora y esperanzada del cardenal Scola. Reflexión que no quiere moverse ni quedarse en la cuestión teórica, que no aportaría nada nuevo, ni dar por sentado nada más que el anhelo del corazón humano. Si el cristianismo tiene algo que aportar, precisamente, no es nada de lo que el hombre postmoderno ya ha descartado (teorías, ideales, estructuras, normas...) sino un encuentro personal con alguien que ama ese corazón dolido y sufriente. De ahí el título «¿Postcristianismo?», pues la propuesta cristiana se renueva en una sociedad que, al menos formalmente, ha sido cristiana, pero que no reconoce en Cristo a la persona que colma los anhelos de su corazón.

Las reflexiones de Scola se dividen en dos partes: una primera en la que describe los rasgos claramente postcristianos de la sociedad occidental, y una segunda propositiva, en la que contrasta la propuesta cristiana con la experiencia del hombre que en esa sociedad descrita siente cómo su corazón palpita al ritmo de las preguntas más radicales que no puede dejar de hacerse. Antes de entresacar alguna de las reflexiones que me parecen más sugerentes o provocadoras, quiero dejar constancia de los temas abordados en ambas partes para que quede una idea más precisa de todo el contenido del libro, no sólo de la perspectiva desde la que se aborda, que es la descrita hasta ahora.

Así, en la primera parte, aborda el análisis de cómo la sociedad actual se enfrenta a las cuestiones y retos que le plantean la pluralidad religiosa, la laicidad, el encuentro con el Islam, la economía, la ecología y la paz. Y en la segunda, la propositiva desde la fe cristiana, el núcleo de la propuesta y el hecho cristianos, Cristo, la Iglesia, el testimonio y el martirio.

Ya digo que al seleccionar las cuestiones que me parecen más sugerentes me voy a mover por criterios completamente particulares, pero creo que al hacerme eco de este libro en un entorno universitario, son aquellos que interpelan también las cuestiones teóricas más de fondo.

La primera es la apelación a qué temática queremos que atiendan las narrativas con las que buscamos explicarnos lo que sucede: ¿se detienen más en los aspectos de disgregación o en los constructivos? En la crisis de un cambio de época esto es crucial: cambia la disposición de fondo y la mirada, tanto sobre la representación política o la comunicación. En la primera caemos en la paradoja de que «la proclamación de la exigencia de libertad acaba por quedar prendida de una red de leyes cada vez más tupida» (Scola, 2018: 20). Y la segunda no incide solo en la dimensión social, sino que también 
afecta al hombre en su capacidad de reflexión sobre sí mismo, de descripción de sí mismo [...]. Vivimos fragmentados en una infinidad de informaciones, conocimientos y saberes hasta el punto de que, cuando afrontamos un aspecto de nuestra existencia, es como si nos olvidásemos de todos los demás (Scola, 2018: 21).

Utiliza el ejemplo de Job para representar dos cuestiones cruciales en el modo en que el cristianismo ha de salir al encuentro de esta sociedad. Job plantea, en primer lugar, una acusación contra Dios a quien le demanda razones para el sufrimiento de un inocente. Solo desde la formulación de los porqués podemos salir del caos de la fragmentación del mundo en que ha caído la comunicación. Yendo a la raíz, y en segundo lugar, Dios mismo acepta el reto de Job, de atender la razón humana que le convoca ante su tribunal.

La crisis política puede ser vencida solo por interlocutores capaces de reabrir y dilatar el deseo del hombre. Si el cristianismo no sabe dialogar adecuadamente y teme asistir a la escuela de las preguntas del hombre para acogerlas y abrirlas de par en par, está destinado a ser un postcristianismo, una especie de anestesia demasiado débil $y$, a estas alturas, inútil a la hora de afrontar los dolores del parto (Scola, 2018: 23).

Desde la valentía de este salir al encuentro de las preguntas del hombre, me parece interesante destacar, por ejemplo, la mano tendida que ofrece al Islam para juntos afrontar el reto de la secularización: “Como hombres religiosos, ¿somos antimodernos o posmodernos?» (Scola, 2018: 26). Con el análisis de Taylor sobre la secularización, admite que el núcleo serio supone ir más allá de que las instituciones estatales no se consideran vinculadas con ninguna religión, o de que haya una disminución de la práctica y la creencia religiosas, sino si se considera la fe en Dios no como una opción radical, sino como una más entre otras. Con lo que la pregunta por el sentido y el significado profundos de la vida y la sociedad necesita plantearse de manera radicalmente nueva, en un horizonte de reflexión en el que han de tener cabida los distintos sujetos interlocutores que tienen una propuesta al respecto.

\begin{abstract}
Todas las cuestiones que han aparecido hasta ahora, de cara a volver a pensar una nueva laicidad para una sociedad postsecular, conducen a un punto de partida común: el bien práctico del estar juntos. Todos vivimos, y no podemos no hacerlo, cada uno con su propia visión, en la misma sociedad en búsqueda de un bien concreto, vivible y que pueda ser compartido. El bien práctico del estar en sociedad constituye el fundamento de ese «universal político» que el proceso de secularización ha perdido a lo largo de la modernidad (Scola, 2018: 29).
\end{abstract}

La autoridad política, por tanto, ha de asumir un papel aconfesional e imparcial, sí, pero no neutralista, por cuanto ha de promover los dos niveles constitutivos de lo político: «el reconocimiento del valor del bien común práctico-social del estar juntos y el reconocimiento de los valores específicos que la continua negociación reconocerá poco a poco como tales, según el criterio, formulado por Rawls, del "consenso por intersección"» (Scola, 2018: 30). Apuesta así el cardenal por un realismo político fundado sobre el valor mismo del estar en sociedad y no sobre procesos formales abstractos. 
La cuestión de cómo la construcción de un modelo de «universal político» no puede construirse neutralizando las diferentes propuestas religiosas, a mi juicio, tiene un particular interés en la medida en la que realmente pone en ejercicio un diálogo intelectual serio en el que se convoca a todos los implicados a participar: sociedad, Estado y religiones. La neutralización puede provocar reacciones fundamentalistas, que por su parte, tampoco atienden a la exigencia de ofrecer su pretensión de sentido a los interlocutores de una sociedad plural.

Continúa en el capítulo 3 ahondando en la cuestión de la laicidad, que tiene siempre la dificultad de abordarse desde una separación radical entre lo profano y lo sagrado. Hay multitud de cuestiones que califica, con una expresión de Maritain, de «mixtas» (vida, muerte, matrimonio...) en las que es inevitable la presencia de la Iglesia y su palabra. ¿Cómo redefinir la laicidad para no tergiversar la necesaria autonomía de las realidades terrenas? De nuevo la propuesta es práctica, no teórica: «aceptar la inevitable divergencia de las visiones del mundo, aportando al mismo tiempo por la posibilidad de entenderse concretamente sobre lo que hay que hacer» (Scola, 2018: 41). Puede haber una buena salud de lo político sin pleno acuerdo sobre lo que hay que hacer por un lado, y sin exclusiones secularistas de lo religioso por otro. Finalmente, al cristiano le toca hacer su propuesta «exponiéndose» a sí mismo, esto es, dejando que su vida deje transparentar la plenitud de lo humano que se cambia su vida.

Me gustaría concluir, precisamente, con la categoría central del testimonio (capítulo 12), «lugar de encuentro entre la espera del Salvador por parte del hombre contemporáneo y la contemporaneidad del Resucitado, confesado y anunciado por la comunidad cristiana» (Scola, 2018: 121). En otras palabras, es el lugar donde los cristianos podemos cooperar con nuestros contemporáneos en pro de la esperanza. No podemos reducirlo a buen ejemplo, aunque es necesario. Lo esencial del testimonio reside en ser referentes de otro que se comunica. Por eso ni en lo social, ni en lo político, lo cristiano puede traducirse en utopías concretas. Dejarían de ser apelación a Alguien que no se agota en el tiempo.

En el testimonio y en el narrar de sí mismo, el testigo cristiano comparte personalmente al menos un fragmento del deseo de plenitud que nunca se apaga del todo en el hombre, vuelve a despertar en su corazón la esperanza y, por tanto, la nostalgia de Dios, destino del hombre, fuente y culmen de su felicidad (Scola, 2018: 128).

Hacia el final del capítulo muestra cómo nadie debería temer la presencia de Dios en la vida social y personal, porque los cristianos no deberíamos aspirar a dominar, sino solo a poner en práctica el propio método de Jesús, el testimonio que sabe «hacer de su diferencia específica el camino de una propuesta humilde y tenaz. De este modo, encontrarán el insuprimible anhelo de esperanza de los hombres, que siempre es deseo de Dios (Scola, 2018: 130).

AGEJAS ESTEBAN, José Ángel 